\title{
E-LEARNING INFRASTRUCTURE PROTOTYPE FOR GEOGRAPHICALLY DISTRIBUTED PROJECT-BASED LEARNING
}

\author{
N. Becattini ${ }^{1}$, S. Škec ${ }^{2, \otimes}$, N. Pavković ${ }^{2}$ and G. Cascini ${ }^{1}$ \\ ${ }^{1}$ Politecnico di Milano, Italy, ${ }^{2}$ University of Zagreb, Croatia \\ $\bigotimes$ stanko.skec@fsb.hr
}

\begin{abstract}
The paper presents the original integration of ICT tools and e-learning platform into an infrastructure to support Project-based learning for a design class that is geographically distributed across different countries. 30 Mechanical Engineering students from 4 European countries tested the infrastructure prototype for the development of an innovative solution in the field of white goods. The results produced evidence about the suitability of the proposal together with strong and weak points of the infrastructure, that can support further development and adaptation into different contexts.
\end{abstract}

Keywords: e-learning, project-based learning, design education, collaborative design, distributed design

\section{Introduction}

Engineering education efforts are paid to the development and reinforcement of paradigms to enhance the learning process of students, and a growing body of contributions show the potential of students' involvement in real industrial projects (e.g. Dym et al., 2005). This learning-by-doing approach, namely Project-Based Learning (PBL), aims at building engineering skills for students by confronting them with design problems that match their future professional profile (e.g. multidisciplinary projects to be developed in teamwork). This fulfils two objectives. On the one hand, it improves their skills directly related to engineering design. On the other hand, this fosters their attitude towards permanent education in an adaptable life-long learning process. Within PBL courses, students are confronted with realistic, complex and ill-structured project tasks. Based on many research and expert reports, elearning as an approach can support students significantly in design PBL courses regarding both contextual and collaborative learning (Verstegen et al., 2016). Contextual learning includes a provision of a realistic, authentic and simulated learning environment to enhance understanding of the content that is being taught, while collaborative learning implies the usage of communication (synchronous or asynchronous) tools for both technical and non-technical information and knowledge exchange. Within the engineering domain (but also many other domains), there are still many issues in implementing both aspects of contextual and collaborative learning (Dederichs et al., 2011). Various ICT tools, used throughout design PBL courses, showed their applicability for some design-related activities (e.g. project management). However, issues regarding more creative activities still remain unsolved. Besides ICT tools for general communication within virtual student teams, design PBL courses often require the usage of special engineering applications (such as Computer-Aided Design 
(CAD), Computer-Aided Engineering (CAE), Product Lifecycle Management (PLM)). Usage of these tools is one of the most important and widely adopted practical skills that have to be acquired during design education. These tools facilitate the analysis and visualisation of products being developed in various phases (conceptual phase, embodiment phase, detail phase) and thus foster group creativity and problem-solving abilities.

The paper presents the early results of an international Erasmus+ project (ELPID). It aims at developing an e-learning infrastructure through the combination and adaptation of existing e-learning tools, platform and approaches. The infrastructure is to be used within design PBL courses by a multinational class distributed across various countries that interact from a distance. To do so, the proposed e-learning infrastructure embraces existing Web and other ICT technologies that can facilitate technical and nontechnical knowledge and information exchange and foster creativity and problem-solving in virtual PBL courses. The assumption is that this integration provides students with an effective e-learning infrastructure. This study provides an essential starting point to consolidate such infrastructure and hints how to develop a methodology to customise it for other courses sharing similar characteristics.

The next section summarises relevant contributions from the literature, which led to the definition of the general e-learning infrastructure (presented in section 3). Section 4 details the outcome of a first design PBL course (with 30+ Mechanical Engineering students from Croatia, Italy, Austria and Slovenia), which worked as a test-bench for the prototype of the e-learning infrastructure. The implications of these outcomes are discussed in section 5.

\section{Research background}

\subsection{Design project-based learning}

Project-based courses and learning, to be more general, are always organised around central project or problem that needs to be solved (Ribu and Patel, 2018) and results with tangible products (Blumenfeld et al., 1991). As such, in most cases, PBL follows a social constructivist approach to learning (Guthrie 2010) and equips students with sustainable and transferable skills that support the self-directed and collaborative learning of domain-specific knowledge. Therefore, in comparison to traditional didactic instructions, PBL often offers various advantages such as a resemblance to the industrial reality and the focus on the knowledge application (Grimheden and Hanson, 2005).

In traditional design courses, students are often exposed to "context-free" teaching of mathematics, basic sciences and engineering sciences without any practical engineering application (Vidovics et al., 2016). Conversely, the primary purpose of the design PBL courses such as KaLeP design course (Albers et al., 2009), EGPR (Vukasinovic and Pavkovic, 2017) or GPD (Leung et al., 2019) is to provide students with the experience of developing products in distributed and multidisciplinary environment with an industrial partner. During these design PBL courses students gain hands-on knowledge on different phases of the product development process - analysis of user needs, planning, concept development, embodiment, detailing and prototyping. Therefore, this type of courses completely differs from traditional and conventional engineering courses due to its learner-centred teaching strategy (Hou et al., 2007) and intended learning outcomes. The PBL course type enables the development of students' capabilities to communicate, collaborate and make decisions related to different phases and aspects of design. In addition, students can additionally improve their planning, reporting and knowledge-sharing skills (Hou et al., 2007) and, consequently, become better prepared for design real-world settings.

In order to facilitate the execution of PBL courses, certain efforts have been taken to adapt and contextualise e-learning tools and approaches for this course type.

\subsection{E-learning adaptation for the PBL context}

E-learning stands for a set of learning forms that enable the digital transfer of learning content and covers a wide range of digital learning activities to support overall student experience (Loy, 2014). It is also perceived as the use of technology to deliver, support and improve both teaching and learning. As such, it allows many possibilities for the integration of multimedia and various other contents to enhance the autonomous learning process. Although initially developed to facilitate individual and 
self-directed learning, e-learning platforms also offer multiple benefits in terms of collaborative learning and, thereby, are aligned with PBL learning strategies. Therefore, the use and exploitation of e-learning and computer-mediated environment within the PBL courses became an emerging topic within the last two decades.

Few previous attempts were mostly related to creating a general e-learning approach for the whole curriculum (e.g. Banday et al., 2014). However, they were not focused on building the e-learning platform for project-based learning courses. There are several research and expert studies that show to what extent e-learning can support PBL. For example, use of multimedia in PBL courses can provide "hidden" contextual information such as visual, auditory, or other nonverbal cues which are usually missing in paper presentations or lectures (Hung et al., 2008). Also, e-learning tools have been used extensively for distance-based PBL and to structure the interaction within the student team and between students and others (e.g. educators, industrial partners). However, it was already mentioned that some e-learning modules could support and, actually, hinder PBL (Barrows, 2002; Verstegen et al., 2016). As such, a plethora of e-learning tools has not succeeded in facilitating and stimulating collaborative work. For that reason, to ensure its success, an e-learning platform should support following PBL principles and processes (Verstegen et al., 2016), which are also needs to be satisfied:

a) activation of prior knowledge,

b) elaboration, argumentation, critical thinking,

c) structuring and restructuring of information,

d) collaborative learning,

e) learning in context,

f) self-directed learning.

Currently, these PBL principles and processes have been only partially addressed within the analysed design PBL courses, and further attempts are needed for tackling this issue.

Within the design community, only a few studies addressed the introduction and tailoring of the elearning environment within design PBL courses. However, they only focus on a specific tool that was used within a particular course, without following PBL theoretical foundations and providing a comprehensive e-learning framework for PBL education. For example, Albers et al. (2009) reported usage of various information and communication technologies such as Wikis and PDM to support distant collaboration among students. Randeree (2006) indicated that the development of the new engineering design course requires multiple e-learning tools such as web delivery, multimedia and domain-specific software tools. Moving to non-technical tools, Brisco et al. (2017) emphasised the role of social networking as a communication and collaboration platform.

Building on these insights, the overarching aim is to embrace these previously disparate elements like specialised engineering tools, various multimedia content and non-technical communication tools into a comprehensive e-learning infrastructure to develop and test. In addition, e-learning approaches for PBL are often detached from the learning objectives and developed without systematic consideration of content and the way it is presented. Because of the variety of aspects to consider, the development of such infrastructure represents a major challenge. As the initial step, in the next section, the concept of e-learning infrastructure contextualised for the design PBL environment is proposed.

\section{Proposed e-learning infrastructure}

Based on the literature review and preliminary insights from previous editions of PBL courses, the main objective was to propose e-learning infrastructure that should be tailored for the PBL context according to the previously mentioned specificities, principles and processes. It has to cover the basic theoretical design background for the project through textual, audio and video material. Besides, it needs to integrate virtual and digital technologies to provide students with the opportunity for collaborative and creative problem-solving in design, to avoid students go through educational materials traditionally, which is against the PBL principles of constructive and self-directed learning (Verstegen et al., 2016). Therefore, it is crucial to rethink and adapt the existing platforms so that the new infrastructure organically encompasses three different aspects: contents for design, collaboration in design and lecturer's needs. Figure 1 shows the general layout of the infrastructure detailed in the next subsections. 


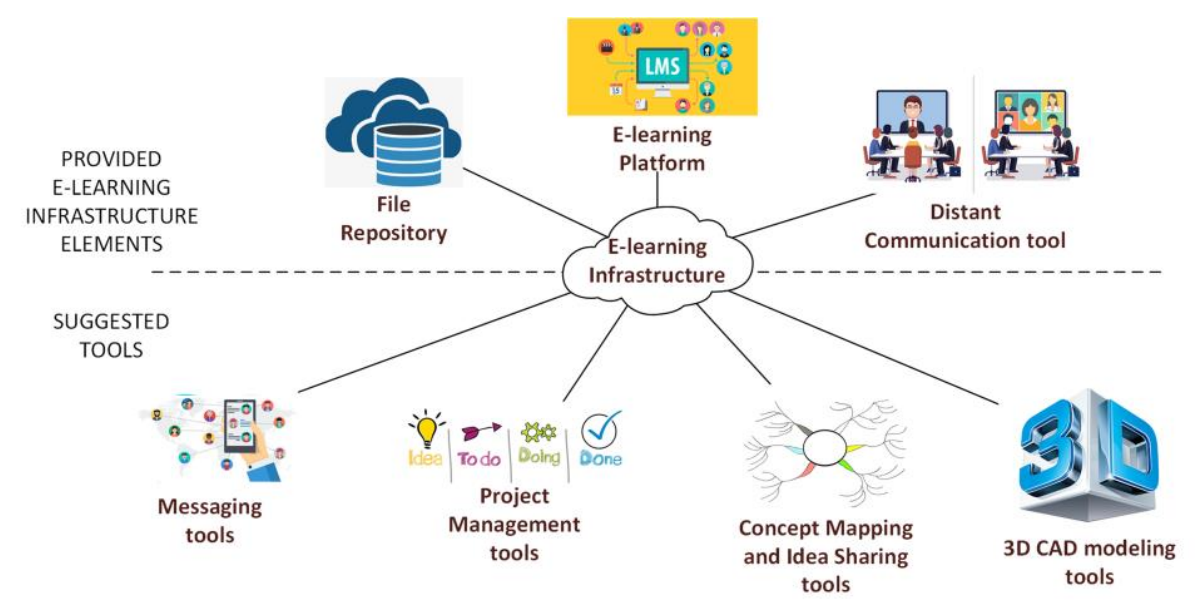

Figure 1. E-learning infrastructure prototype (integration of platform, repository and tools)

\subsection{Content aspect within the e-learning course}

Currently, the existing e-learning platforms are often perceived only as a document repository with no practical value for design PBL courses. Yet, Learning Management Systems (LMS, as Moodle) help to store teaching material and course calendar. For more effective learning in the design PBL course, these materials also have to include lecture video recordings, presentation files, guidelines for conducting certain design activities (e.g. how to build a storyboard, how to make patent search/analysis, etc.) and templates for reporting activities in a user-friendly and transparent manner.

\subsection{Student collaboration within the e-learning course}

The teamwork activity in design PBL courses requires quite frequent communication, and therefore there should be a variety of e-learning modules and tools that foster these course aspects. Furthermore, the inherent limitations of LMS and various virtual tools point to the need for adapting the support to the different phases of design projects. For example, sketches facilitate communication during the conceptual phase, while throughout the embodiment phase, students utilise CAD and PDM tools for exchanging engineering information. Ferreira de Farias et al. (2016) criticised LMS Moodle for its inadequate support for more demanding PBL implementations. Although Moodle provides various modules such as Gantt chart, Calendar, Design project or Activity Panel, students do not perceive them enough intuitive and flexible. Then, the existing LMS for design project-based courses can be mostly used as the main hub of the e-learning infrastructure for the provision of information about how to access multiple tools at one place. In fact, scholars such as $\mathrm{Ku}$ and Chang (2010) argue that traditional LMS often do not sufficiently support the collaborative learning experience. For example, wiki systems intended for building collective text are frequently replaced with word processing apps such as Google Docs. As such, the proposed infrastructure facilitates accessing these tools for preparing project reports and tracing their work progress. To organise the workflow and sequence of activities, the infrastructure facilitates students to access project management tools (e.g. Trello and Slack), in case the LMS functionalities (e.g. Mahara in Moodle) are not adequate. For exchanging technical information, students can share concepts via communication tools integrating whiteboard and screen sharing functionalities (e.g. Adobe Connect), as well as CAD and PLM tools: this helps addressing the needs highlighted in the bullet list (a-f) in Section 2.2. Ferreira de Farias et al. (2016) suggest that various virtual resources should be employed to foster active learning style. For that reason, the students who tested for the first time the infrastructure presented here were also told about the existence of cloud-based applications that can help them bypassing obstacles with exchanging files created in various proprietary software packages (e.g. Onshape). OwnCloud is used as a file repository to synchronise and share the created outputs among students and educators during the design process (to share relevant, current and prior, knowledge - a). The tools were selected according to the functionalities they can provide along the design process. Students were left free to use the tools they prefer and received suggestions for free. 


\subsection{Integration of educator's aspects of the e-learning course}

LMS should support educators throughout the course to organise the activities, e.g. design reviews, and to monitor the progress of students. The proposed infrastructure enables the tracking of students' performance. Educators can analyse the frequency and type of e-learning activities on the LMS learning analytics modules as well as the dynamics of file versions on the repository. Second, the LMS enables creating questionnaires/quizzes to collect students' feedback on their performance, motivation and satisfaction. In addition, educators can easily communicate through the e-learning platform in a more formal manner and organise weekly online meetings (e.g. via Adobe Connect) with their respective teams for synchronous communication and knowledge exchange with team members. An additional LMS feature, crucial for the course reporting, is related to grading of student performance and its coupling with learning outcomes. Therefore, this aspect should not be neglected in the longterm by educators.

\section{Geographically distributed design project course: structure, results and main evidence}

\subsection{Description of course}

The whole course is essentially structured coherently with the stages of a product development process, and particularly those that focus on the identification of opportunities to the generation and the engineering of an innovative product capable of facing the market challenge. The students were organised into four groups composed, on average, of 8 subjects from different institutions to foster collaborative learning. To foster contextual learning, they were asked to focus their design project on the development of an innovative thrash bin ready for a market launch. This project was done in collaboration with BSH/Bosch Siemens Hausgeräte, which provided students with a design brief on a small appliance for domestic use - a smart garbage bin). The course had three main phases to facilitate the execution of project activities and provide the students with a clear pace for their design tasks. In the end, the students gathered for a one-week workshop. There they could refine their solutions and prepare posters and presentations that they used to show their ideas in front of the company executives. Table 1 summarises the phases of the project.

Table 1. Syllabus of the PBL-based course supported by e-learning methods and tools

\begin{tabular}{|c|c|c|c|}
\hline Phase of the project & Duration & Goal of the phase & Topics of the lectures \\
\hline $\begin{array}{l}\text { Fuzzy front-end } \\
\text { (1st phase) }\end{array}$ & 4 weeks & $\begin{array}{l}\text { Vision and requirements } \\
\text { for the solution }\end{array}$ & $\begin{array}{c}\text { - Project \& Phase } 1 \text { introduction } \\
\text { - Presentation of the case-study } \\
\text { - Communication and teamwork } \\
\text { - Market Research } \\
\text { - Techniques and methods for conceptual } \\
\text { design }\end{array}$ \\
\hline $\begin{array}{c}\text { Conceptual } \\
\text { development } \\
\text { (Conceptual design - } \\
\text { 2nd phase) }\end{array}$ & 5 weeks & $\begin{array}{l}\text { A set of promising } \\
\text { solution concepts }\end{array}$ & $\begin{array}{l}\text { - Phase } 2 \text { introduction } \\
\text { - Methodology of 3D CAD modelling } \\
\text { - Introduction to Computer-Aided } \\
\text { Engineering } \\
\text { - User centered and pervasive design }\end{array}$ \\
\hline $\begin{array}{c}\text { Elaboration } \\
\text { (Embodiment/detail } \\
\text { design - 3rd phase) }\end{array}$ & 3 weeks & $\begin{array}{l}\text { Detailed concept and } \\
\text { technical documentation }\end{array}$ & $\begin{array}{l}\text { - Phase } 3 \text { introduction } \\
\text { - Electric Propulsion, drives ad motors }\end{array}$ \\
\hline $\begin{array}{c}\text { Presentation and final } \\
\text { evaluation ( } 4 \text { th } \\
\text { phase) }\end{array}$ & $1+1$ weeks & Virtual prototypes & - Live workshop (no lectures) \\
\hline
\end{tabular}

The design and project management activities were also supervised by one or two senior coaches per group that regularly met students through ICT tools that enable distant collaboration/communication. 


\subsection{Data collection procedure}

Data collection embraced subjective feedback obtained directly from students and data captured within the e-learning infrastructure on the usage of the e-learning platform. At the end of the course, students provided their qualitative and subjective feedback to coaches (which reported the contents of semi-structured interviews). This enabled the assessment of the characteristics and the usability of elearning infrastructure prototype. The feedback also highlights potential gaps to fill in order to overcome current drawbacks and steer further developments.

In details, by means of the semi-structured interviews that coaches conducted with respective team members, the students provided their feedback on the following aspects:

- Role of technology to enable collaboration (technology/collaboration-wise)

- Type of specific tools used along with the three main phases of the PBL activities (as depicted in Figure 1)

- Number of people using e-learning tools per group and the role of tools in facilitating individual work and distant interaction

- Suitability of the infrastructure to enable efficient knowledge sharing and communication

- Frequency of interaction among group members by means of face-to-face and distant interaction

- Adequacy/comprehensiveness of contents provided by the infrastructure for the project

- Availability of contents, also by phase (including those self-retrieved)

- Modality of content sharing from educators (lecturers and coaches) to students

To validate the insights obtained from the subjective feedback, additional analysis was conducted of the $\log$ data (objective) already captured within the e-learning infrastructure. These data sources included the $\log$ files with the number of different functionalities and resources that students used during the courses, the number of e-learning features that the majority of participants used, etc.

The occurrences for the above data determine the students' adoption of the e-learning infrastructure throughout the PBL course. In principle, the same can also be done for the activities of educators. The ultimate goal of the above investigation is to better tailor current e-learning infrastructure according to the PBL needs and, finally, to allow students and teachers to improve the intended learning outcomes.

\subsection{Analysis and discussion of the collected results}

\subsubsection{Students' qualitative/subjective feedback}

The feedback provided by students during the interviews conducted at the end of the project allowed spotting both strong and weak points of e-learning support throughout the project execution.

From the perspective of the technological means used and accessed during the three main phases of the project, the students relied on a wider set of ICT and Web tools, compared to what the e-learning platform prototype offered them (see Figure 1). To facilitate communication, to make it easier, faster and accessible, all the groups created dedicated chats with WhatsApp. The dynamics of communication was different among groups, as some preferred to have one-to-one interaction between students and coaches, while others created a shared WhatsApp chat with the coach. Some teams also used project management tools such as Slack (slack.com) and Trello (trello.com). The former facilitated planning meetings, compared to Moodle, as well as file sharing. It made information access and communication via smartphones easier, also because of the availability of notifications (which are lacking or more complicated to set with Moodle). The latter (Trello) has the advantage of supporting the definition of tasks and the definition of responsibilities, thus supporting project management in an easier way. The wide diffusion of WhatsApp and smartphones made the adoption of this communication channel easy for all the team members. The rate of adoption for Trello and Slack was also high as they were used at least by two groups out of 4 . All the groups also used Adobe Connect for online meetings, as evidence that one meeting room per group in the infrastructure served its purpose. It proved to be effective for discussions and idea exchange via screen sharing, despite its performance strongly depends on the network capabilities of each point of access. Besides, the 
compatibility of microphones and earphones with the system was mentioned as critical (groups referred to sound distortion and communication lags). The lack of hierarchy for the subjects accessing the platform sometimes made the communication also chaotic, due to voice overlapping and the absence of a clear policy to take the floor. Differently from instant messaging systems, Adobe Connect was used from once to $2 / 3$ times per week by all the teams, to run internal meetings and formal meetings with coaches (approximately once per week). In terms of distant collaboration, students also reported more frequent face-to-face interactions among school mates, as they were sharing the same space at universities. To share contents, students also shared files by email and through the OwnCloud repository, where they managed file versions by means of self-defined group policies. For what concerns the use of CAD tools to develop their own ideas and share them with others, some groups also decided to access and create their own repositories in the existing platform for sharing of $3 \mathrm{D}$ models, such as GrabCAD.com and traceparts.com. Reusing existing 3D models from various CAD tools, as well as integrating their CAD models created with the software their home institution allowed them to use (e.g. Dassault SolidWorks and Catia v5, Autodesk Inventor Pro, Siemens NX), required the students (also within the same group) to use STEP files. For this reason, all the students clearly mentioned the need of using a CAD tool that facilitates sharing and reusing 3D models, potentially enabling concurrent modelling activities through online platforms (e.g. by using Onshape or 3DExperience by Dassault). The advantages of concurrent collaboration were extremely appreciated when students have to prepare reports at the end of every course phase (e.g. by Google docs).

For what concerns the contents provided through the platform, students positively reported the possibility to access the lectures on the Moodle platform. They said that they typically downloaded presentations of the lectures. Some group members also mentioned that they accessed Moodle to view the recordings of the lectures and focus on specific contents to reuse and apply during project execution. Students also accessed some of the additional contents provided by educators (e.g. guidelines for project phase execution available on OwnCloud repository) to steer their design activities and better understand how to carry out the activity and what to do in practice. Regarding the effectiveness of content, the students generally expressed a preference for contents (lectures and guidelines) provided in a schematic and visual form, compared to more traditional written text. They would also like to rely on more concrete and elaborated examples that show the direct application of methods and tools presented in lectures, that in some cases were just presented theoretically. These examples have been sometimes provided by coaches during live meetings, especially for the activities the students were less familiar with (e.g. those in phases 1 and 2). Nevertheless, although the pedagogy based on social interaction (Bandura, 1977) has already proved to be effective in learning contexts, the distant interaction that took place in online meetings with coaches created some barriers. Screen sharing, by itself, was not capable of overcoming them, resulting in a harder process of knowledge acquisition from students.

\subsubsection{Platform-based analysis of project data}

The log files and the analytics provided by the Moodle platform used within the project allowed the extraction of relevant data to validate some of the evidence captured during the interviews. Figure 2 shows the number of interactions that the whole set of students had along the course duration with the Moodle platform.

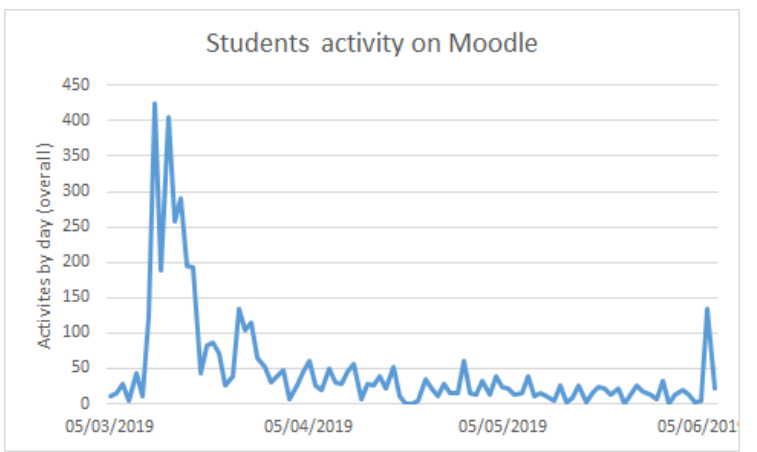

Figure 2. Number of activities that students carried out by date 
These data clearly show that the amount of interaction (and thus the frequency) was significantly higher during the first two weeks of the course. This is due to two main reasons. First, the necessity, for students, to start learning what the platform functionalities are and which, among these, could be proficiently used as a support for the execution of the project. Second, at the beginning of the course, two groups started using the platform to plan their meetings, and every timeslot selection resulted in one new action for Moodle analytics. After this initial trial, they switched to instant messaging for this. Independently from this second reason, within a time frame of two weeks, the students' learning curve about platform functionalities was practically fully developed. The rate of interaction, in fact, significantly decreases and remains constant until the end of the project, when a new peak appears. This is due to the need of accessing the platform to provide their final personal evaluation of the whole course (which is not considered here) and retrieve specific supporting materials to finalise the project documentation - the posters to describe their solution as well as the presentation to be delivered in front of the officers of the white goods company.

Figure 3 presents two graphs to complement the information presented in Figure 2.

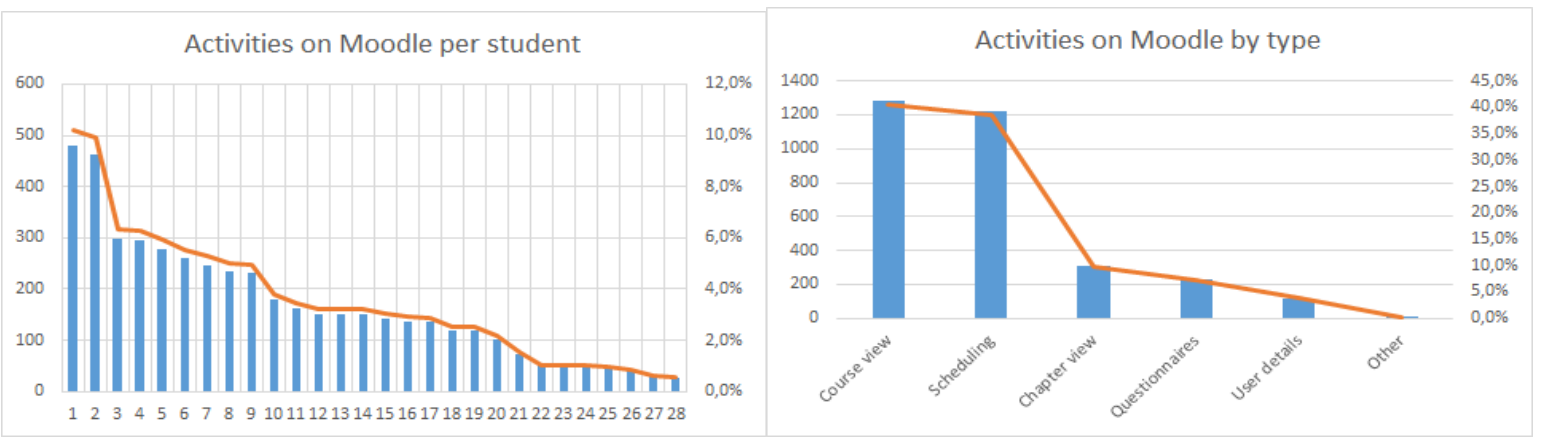

Figure 3. Activities carried out with the moodle platform. Left: distribution of the number of activities per student during the whole class. Right: distribution of the number of activities by type during the whole class. (Blue histograms: left $y$-axis; Orange line: right $y$-axis)

The one on the left-hand side shows that, among the whole set of students involved into the activity (33 overall), 5 of them did not access the Moodle platform, as its analytics collected logs of actions for just 28 of them. Moreover, the distribution of actions/activities done on the Moodle platform is significantly spread among the 28 students that used it, as two of them carried out almost the $20 \%$ of the overall set of activities/actions. On average, the students interacted with the platform 167 times each, during the three months of the project duration (standard deviation: 120). This means that, on average, each student used Moodle for 9 actions (the same or different ones) every 5 days. As there is no clear reference to compare these results with, it is also hard to argue if the number of measured activities/interactions with the Moodle platform could be considered sufficient or not. On the other hand, the fact that these data are so spread among participants indicates the need for some corrective actions. These corrective actions should aim at facilitating all the students to interact with the platform and making them more familiar with its modules (e.g. a reduction of the standard deviation will turn into a more uniform use of Moodle by students, meaning that its functionalities are really useful and needed).

The graph on the right-hand side presents the number of activities done with the Moodle platform during the whole project duration, organised by type of activity. Activities have been clustered into 6 main classes: Viewing the course (e.g. organization of lectures, dates...); Scheduling (e.g. planning meetings and group deadlines); Viewing teaching materials (e.g. downloading presentations and video-recorded lectures), Answering questionnaires and look for other platform users details (e.g. contacts and description of groupmates or coaches). These numbers clearly show that some of these activities are poorly exploited by students such as Chapter View or User details view. This is consistent with what the students declared during the ex-post class interviews about the use they made of Moodle. As most of the groups scheduled their meetings utilising less formal and more prompt tools (e.g. instant (group) messaging apps like WhatsApp), the results concerning "scheduling" activities should not be interpreted just as the planning of meetings, but also as access to the calendar of lectures. In any case, most of these actions were done during the first two weeks of the project, 
which means that most of the "real" actions on Moodle were focused on the access to teaching contents and answering questionnaires.

From this perspective, it would be necessary to complement the current infrastructure embracing the Moodle platform, Adobe Connect and OwnCloud file repository with functionalities that allow students to run an increased range of activities. These activities can be nowadays carried out more intuitively and quickly through other tools and applications such as those accessible through their mobile phones, leading to the next step of infrastructure development.

\section{Implications}

The results presented in section 4 witness that the adoption of learning analytics provides useful complementary data to double-check what can be recorded employing more traditional approaches with students (e.g. discussions on teaching topics, verification of learning outcomes, exams). These data can indicate whether learning activities are effective and when students struggle during the course (e.g. by means of platform/infrastructure access logs in a time perspective). As such, they may serve as a guide for further improvement of existing PBL course and teaching/learning experience as well as to gather important insights for a more adequate e-learning infrastructure. These insights can then lead to innovative designs for the learning process, both from the perspective of content and communication to facilitate knowledge acquisition through PBL practice.

In addition, traditional design courses based exclusively on textbook and ex-cathedra teaching are nowadays more commonly replaced by PBL that includes blended activities - both virtual and physical. For that reason, the transferability potential of these research finding seems to be very high since project-based learning became an increasingly popular teaching strategy. The findings presented in Section 4, therefore, can be considered valid for a class of mechanical engineering students. Nevertheless, the proposal of such e-learning infrastructure and the associated e-learning customisation methodology could have various implications for course development in different educational fields. In such a case, this requires tailoring the infrastructure to needs of PBL in different domains and disciplines. As the overall needs to carry out the activities of the conceptual stages of design are essentially similar across disciplines, project management, as well as communication and idea-sharing tools, should be of easier cross-discipline implementation. Conversely, the more domainspecific design stages, e.g. those dealing with the latest stages of the development of solutions, will require a more significant adaptation. For instance, these adaptations can be related to 2D CAD modelling tools for architecture designers, surface modelling and more advance rendering tools for industrial designers, collaborative-coding platforms for computer science, etc. The multidisciplinary project will need the adoption of more tools to support embodiment/detailed design.

Also, implementation of this type of e-learning infrastructure to more different project-based learning courses, with learning analytics modules, would allow monitoring a long-term achievement of learning outcomes across the institution. Still, it is important to emphasise that the proposed e-learning platform in a current form has a lot of space for improvement. Specifically, it requires significant additions and modifications to address PBL principles and processes such as self-directed learning, argumentation and critical thinking.

\section{Conclusions}

The paper presents a set of characteristics that an e-learning platform could conveniently embed to support the activities of a PBL design course more effectively and efficiently. A first prototype that integrates existing e-learning platforms (Moodle) and other ICT tools that can support collaboration and project execution have been used within a PBL course geographically distributed in four countries. More than 30 Mechanical Engineering students from Austria, Italy, Croatia and Slovenia worked in groups to address a design task in the domain of white goods and interacted with the e-learning infrastructure prototype. The outcomes of this interaction provide early evidence which shows the lacks of current elearning platforms. Their integration with already existing online tools is needed to effectively support the different stages of the design process and their related activities, such as project management, concept generation, idea sharing in collaborative contexts and embodiment of solutions, besides distant 
communication among team members. These findings can become useful both for the development of future, more adequate, e-learning platforms that support Mechanical Engineering and also suggest how different disciplines should define the infrastructure of similar e-learning tools.

\section{Acknowledgements}

This ELPID project is co-funded by the Erasmus+ Programme of the European Union.

\section{References}

Albers, A. et al. (2009), "Academic engineering design education in a realistic environment", ASME 2009 International Design Engineering Technical Conferences and Computers and Information in Engineering Conference, ASME, pp. 565-573.

Banday, M.T., Ahmed, M. and Jan, T.R. (2014), "Applications of e-Learning in engineering education: A case study”, Procedia-Social and Behavioral Sciences, Vol. 123, pp. 406-413.

Bandura, A. (1977), Social Learning Theory, Prentice Hall, Englewood Cliffs, NJ.

Barrows, H. (2002), "Is it truly possible to have such a thing as dPBL?", Distance Education, Vol. 23 No. 1, pp. 119-122.

Blumenfeld, P.C. et al. (1991), "Motivating project-based learning: Sustaining the doing, supporting the learning", Educational psychologist, Vol. 26 No. 3-4, pp. 369-398.

Brisco, R., Whitfield, R.I. and Grierson, H. (2017), "The use of social network sites in a global engineering design project", In DS 87-9 Proceedings of the 21st International Conference on Engineering Design (ICED 17) Vol 9: Design Education, Vancouver, Canada, 21-25.08. 2017, pp. 059-068.

Dederichs, A., Karlshøj, J. and Hertz, K. (2011), "Multi-Disciplinary Teaching: Engineering Course in Advanced Building Design”, J. Prof. Issues Eng. Educ. Pract., Vol. 137 No. 1, pp. 12-19.

Dym, C.L. et al. (2005), "Engineering design thinking, teaching, and learning", Journal of Engineering Education, Vol. 94 No. 1, pp. 103-120.

Ferreira de Farias, G., Spanhol, F.J. and de Souza, M.V. (2016), The use of LMS to support PBL practices: A systematic review.

Grimheden, M. and Hanson, M. (2005), "What is design engineering and how should it be taught?-Proposing a didactical approach", In DS 35: Proceedings ICED 05, the 15th International Conference on Engineering Design, Melbourne, Australia, 15.-18.08. 2005.

Guthrie, C. (2019), "Towards greater learner control: Web supported project-based learning", Journal of Information Systems Education, Vol. 21 No. 1, pp. 11.

Hou, H.T., Chang, K.E. and Sung, Y.T. (2007), "An analysis of peer assessment online discussions within a course that uses project-based learning", Interactive learning environments, Vol. 15 No. 3, pp. 237-251.

Hung, W., Jonassen, D.H. and Liu, R. (2008), "Problem-based learning", Handbook of research on educational communications and technology, Vol. 3 No. 1, pp. 485-506.

$\mathrm{Ku}$, D.T. and Chang, C.S. (2010, August), "A framework of PBL strategy integrated in LMS and a ubiquitous learning environment", In The 6th International Conference on Networked Computing and Advanced Information Management, IEEE, pp. 722-726.

Leung, W., Wang, Y. and Kim, S.W. (2019), "Global Product Development: project-based multidisciplinary joint course", In DS 95: Proceedings of the 21st International Conference on Engineering and Product Design Education (E\&PDE 2019), University of Strathclyde, Glasgow.

Loy, J. (2014), "eLearning and eMaking in Product Design Education", In DS 78: Proceedings of the 16th International conference on Engineering and Product Design Education (E\&PDE14), University of Twente, The Netherlands.

Randeree, K. (2006), "Active learning strategies in engineering education in Gulf countries", International Journal of Learning, Vol. 12 No. 11, pp. 1-8.

Ribu, K. and Patel, T. (2018), "Systematic integration of project-based learning in an undergraduate humancomputer interaction course: A case study", In DS 93: Proceedings of the 20th International Conference on Engineering and Product Design Education (E\&PDE 2018), London, pp. 656-661.

Verstegen, D.M. et al. (2016), "How e-learning can support PBL groups: A literature review", In Educational Technologies in Medical and Health Sciences Education, Springer, Cham pp. 9-33.

Vidovics, B. et al. (2016), "Development of methodology for distributed collaborative design environment", In Proceedings of the 18th International Conference on Engineering and Product Design Education, E and PDE 2016, The Design Society, pp. 58-63.

Vukasinovic, N. and Pavkovic, N. (2017), "Use of virtual mobility to facilitate modern project-based NPD education”, International Journal of Engineering Education, Vol. 33 No. 6, pp. 2008-2019. 